\title{
Gestão da educação infantil nas políticas municipais*
}

\author{
SONIA KRAMER \\ Pontifícia Universidade Católica do Rio \\ de Janeiro, Rio de Janeiro, RJ, Brasil \\ LEONOR PIO BORGES DE TOLEDO \\ Pontifícia Universidade Católica do Rio \\ de Janeiro, Rio de Janeiro, RJ, Brasil \\ CAMILA BARROS \\ Pontifícia Universidade Católica do Rio \\ de Janeiro, Rio de Janeiro, RJ, Brasil
}

O reconhecimento da educação infantil como um direito (Brasil, 1988) e sua efetivação como primeira etapa da educação básica (Brasil,1996) foram importantes marcos legais da história da educação das crianças. Desde então, essa etapa tem passado por várias mudanças no âmbito das políticas, das práticas e da gestão.

Pesquisar políticas públicas de educação exige considerar três focos: o processo de produção das políticas, a gestão dos sistemas e as práticas das instituições. Em cada um, coloca-se o desafio de considerar o cotidiano, as relações e as produções. Nos três é relevante conhecer a história na sua dimensão de totalidade e as histórias e narrativas daqueles que lideram, concebem, participam do processo.

* Este texto foi produzido no âmbito do grupo de pesquisa sobre Infância, Formação e Cultura (INFOC). Agradecemos a colaboração de: Maria Fernanda Nunes, Patrícia Corsino, Aline Ricci, Camila Reche, Gabriela Scramingnon, Giselle Zlot, Kaelli Marinho, Luciana Chamarelli, Marina Castro, Marta Nidia Maia, Paula Lannes, Rejane Siqueira, Silvia Néli Barbosa. 
Este texto resulta de uma pesquisa ${ }^{1}$ sobre políticas públicas municipais na gestão da educação infantil, realizada com o objetivo de, numa perspectiva macro, conhecer a situação da infância, das políticas de educação infantil e da formação dos profissionais nos municípios do estado do Rio de Janeiro - 15 anos depois de aprovada a Lei de Diretrizes e Bases (LDB) - e de, numa perspectiva micro, conhecer interações e práticas entre adultos e crianças em creches, escolas de educação infantil e escolas de ensino fundamental.

Foram adotadas as seguintes estratégias metodológicas na constituição dos campos empíricos: (1) aplicação de questionário para delinear a situação acerca da cobertura da educação infantil no município, das políticas de atendimento às crianças e da formação continuada; (2) entrevistas com profissionais responsáveis pela educação infantil e atuando em secretarias de educação; (3) observação de práticas de educação infantil em creches, pré-escolas e escolas públicas como parte de estudos de caso simultâneos.

O foco neste texto são as entrevistas e os relatos dos profissionais de educação infantil atuantes na gestão de secretarias de educação de 24 municípios. Vale explicitar que as entrevistas foram fundamentais para delinear os avanços e problemas ainda enfrentados na implementação das propostas pedagógicas, da formação dos profissionais e das práticas nas creches, pré-escolas e turmas de educação infantil que funcionam em escolas de ensino fundamental.

O primeiro item do texto traz o referencial teórico-metodológico, a concepção de pesquisa e como foram realizadas as entrevistas. $\mathrm{O}$ segundo descreve o contexto da pesquisa e o perfil dos participantes da pesquisa. $\mathrm{O}$ terceiro item apresenta resultados e questões relevantes no cenário atual da educação infantil. Por fim, são sistematizadas as conclusões e as prioridades para as políticas.

\section{REFERENCIAL TEÓRICO-METODOLÓGICO E ESTRATÉGIAS DA PESQUISA}

O desenvolvimento e a consolidação de metodologias de pesquisa em ciências humanas e a construção dos dados, de modo que seus significados sejam compreendidos em sua complexidade, requerem um referencial teórico que oriente as escolhas do pesquisador e seu olhar sensível ao campo. A pesquisa em ciências humanas ocorre sempre por meio de estudo de textos: questionários, diários de campo, transcrições e relatórios são objetos de recortes; já o exercício de procurar à distância dá-se como um movimento de aproximação e afastamento, na produção de um conhecimento que é provisório, parcial, que exprime um ponto de vista. A base teórica que orientou essa concepção de pesquisa foi ancorada nos conceitos de Bakhtin $(1987,1988)$, e as entrevistas foram realizadas com a visão de que os

1 A pesquisa teve apoio do Conselho Nacional de Desenvolvimento Científico e Tecnológico (CNPq) e da Fundação de Amparo à Pesquisa do Estado do Rio de Janeiro (FAPERJ). 
relatos têm significados não apenas diversos, mas tensos e contraditórios, pois as palavras expressam forças, valores, intenções.

Quanto às políticas públicas, foram considerados os trabalhos de Ball e Mainardes (2011), Nunes e Kramer (2007a, 2007b), Souza e Faria (2003), Vasconcellos, Aquino e Lobo (2003), entre outros. Ball e Mainardes (2011) abordam as políticas educacionais do ponto de vista teórico-metodológico, ressaltando sua complexidade e a necessidade de relacionar o macro e o microcontexto. Souza e Faria (2003) analisam a municipalização da educação com base na Constituição, discutindo temas como financiamento, gestão dos sistemas e avaliação nos diversos níveis e modalidades de ensino. Vasconcellos, Aquino e Lobo (2003), estudando as repercussões da LDB na educação infantil, notam a resistência dos municípios em assumirem sua responsabilidade por essa etapa da escolarização e a necessidade de integrar ações de educação e cuidado no atendimento à criança pequena. Nunes e Kramer (2007a), em pesquisa sobre políticas de educação infantil no âmbito municipal, destacam o desconhecimento dos profissionais quanto aos dados sobre a educação infantil de seus municípios, o contexto de desigualdade quando comparados os municípios, a precariedade de propostas oficiais para a educação infantil, entre outros aspectos.

As questões centrais desta pesquisa foram as seguintes: qual a situação das secretarias municipais de educação no que se refere à cobertura da educação infantil no município, sua organização e funcionamento, formação de profissionais (ingresso, carreira), instituições, projetos culturais e recursos? Quais as mudanças nas políticas quanto à educação infantil, gestão e formação dos profissionais (professores e gestores)? Que relações de autoridade e autonomia são estabelecidas na gestão? Há avanços e/ou retrocessos? E quais são eles? Que problemas têm sido enfrentados?

Entendidos como questões polêmicas, tais aspectos foram orientadores do trabalho de campo e organizadores do material obtido por meio das estratégias metodológicas, além de se prestarem à contínua modificação e revisão, tanto pelo confronto com a realidade quanto pelo aprofundamento teórico (André, 1995).

A metodologia da pesquisa incluiu - como aqui explicitado anteriormente - aplicação de questionário, realização de entrevistas e observação de práticas em creches, pré-escolas e escolas. A conjugação dessas estratégias de natureza quantitativa e qualitativa favoreceu a compreensão mais ampla do contexto e de sua complexidade. Assim, se, de um lado, o questionário permitiu o levantamento da situação da infância e da educação infantil, de outro foi necessário obter nas entrevistas dados relativos à formação dos profissionais, escolaridade e função exercida, pois que de outro modo não estavam disponíveis.

O questionário foi enviado para 92 secretarias de educação dos municípios do estado pesquisado e foi respondido por 59 delas. Os municípios do estado, de acordo com o número de habitantes, estão organizados pelo Instituto Brasileiro de Geografia e Estatística (IBGE) da seguinte maneira: 30,4\% possuem até 20 mil habitantes; 30,4\%, mais de 20 mil até 50 mil; 28,3\%, mais de 50 mil até 250 mil; $5,4 \%$, mais de 250 mil até 500 mil; e 5,4\% possuem mais de 500 mil habitantes. 
Os 59 municípios que responderam ao questionário estão assim organizados: $22 \%$ possuem até 20 mil habitantes; $33,9 \%$, mais de 20 mil até 50 mil; 32,2\%, mais de 50 mil até 250 mil; 6,8\% apresentam mais de 250 mil até 500 mil; e 5,1\% possuem mais de 500 mil habitantes. Fazendo um contraponto dos dados do IBGE com os 59 municípios respondentes, observa-se que os percentuais relativos ao tamanho da população são próximos à totalidade dos municípios do estado, conferindo representatividade à amostra e permitindo fazer, pela proporcionalidade, aproximações com os municípios que não se fizeram presentes. O questionário incluiu 68 quesitos organizados em seis blocos temáticos: dados gerais do município; sistema de ensino no município, organização e funcionamento da educação infantil no município; formação dos profissionais da educação infantil; ingresso e carreira dos profissionais da educação infantil; recursos financeiros e materiais. $\mathrm{O}$ extenso material relativo aos dados quantitativos obtidos com esse questionário vem sendo objeto também de outros artigos.

As entrevistas, por sua vez, foram realizadas com gestoras da educação infantil de 24 municípios, a fim de identificar e compreender concepções e práticas de gestão dessa etapa da educação. A entrevista foi a opção de estratégia metodológica, considerando, pois, que o conhecimento (nesse caso sobre educação infantil e gestão) é construído também por aqueles que fazem parte da história nas políticas públicas municipais. Em seus relatos, as entrevistadas trataram de problemas, conflitos ou avanços relativos à situação da infância, das políticas de educação infantil e da formação dos profissionais nos municípios, favorecendo a compreensão de processos, contextos e das histórias vividas por equipes e instituições.

Captar ambiguidades, ambivalências, tensões ou contradições (Bakhtin, 1987) relativas à gestão foi o objetivo pretendido com as entrevistas. Ouvindo os relatos, as categorias de análise foram construídas na articulação entre teoria, metodologia e técnica. Bakhtin $(1988,1992)$ chama a atenção para as condições de produção de discursos e a importância de explicitar o contexto para se compreender os textos (falados ou escritos), o que implica aqui situar as condições em que foram produzidos os discursos, práticas e interações, bem como considerar quem foram os entrevistados, o lugar de onde falavam (cargo, formação, vínculo com a secretaria, experiências profissionais anteriores) e as relações de poder que se estabelecem no interior das secretarias e dos sistemas de ensino. Focalizar o olhar nos processos e relações, mais que nos objetos ou fatos, favorece identificar aproximações ou afastamentos, movimentação ou estagnação.

As categorias para a análise das entrevistas foram constituídas pelas vias: (a) da recorrência, considerando os eventos discursivos convergentes que apontaram rumos predominantes das políticas públicas de educação dos governos municipais; (b) da singularidade, com base na especificidade de escolhas de secretarias e seus profissionais, bem como das condições de oferta da educação infantil. Inicialmente foram definidas cinco categorias: gestão da rede, gestão das instituições, formação, concepção de educação infantil, criança e família. Dada essa amplitude, as categorias foram redefinidas com o desafio de agrupar eventos discursivos interligados 
e definir o contorno de cada uma delas, de maneira ao mesmo tempo ampla, para abranger recorrências, e nítida (ou precisa), para assegurar sua especificidade. $\mathrm{O}$ texto concentra a análise na gestão.

$\mathrm{Na}$ organização dessa empiria, foi utilizado o software para pesquisa qualitativa Nvivo 9.0, que apresenta duas formas de acesso ao material de campo: uma permite a visão integral de cada entrevista; a outra permite a visão por categoria, com os eventos discursivos agrupados. Considerando esse aparato técnico e os conceitos bakhtinianos, as produções textuais significativas presentes nos relatos (os trechos de fala) foram identificadas, no tratamento da empiria, como eventos discursivos.

Antes, porém, de analisar esse material, cabe ser apresentado o contexto das entrevistas e o perfil das entrevistadas. Vale esclarecer que as observações feitas nos estudos de caso simultâneos estão em processo de elaboração.

\section{CONTEXTO DAS ENTREVISTAS E PERFIL DAS ENTREVISTADAS}

A escolha dos municípios para a entrevista com os gestores da educação infantil foi pautada nos critérios de densidade demográfica (em particular a população de crianças de 0 a 6 anos) e Índice de Desenvolvimento Humano (IDH). Além desses, foram incluídos todos os municípios localizados na região metropolitana.

Com base nos critérios, foi definida a meta de entrevistar profissionais que atuavam na gestão da educação infantil, em secretarias de educação de 33 municípios. Porém, entrevistas em nove municípios não puderam ser realizadas por problemas de agenda dos profissionais, mudanças de cargo e pelas chuvas intensas no período. Assim, foram feitas entrevistas em 24 municípios entre 2009 e 2011.

Todas as entrevistas foram feitas por dois pesquisadores, segundo um roteiro, e gravadas com a devida autorização da entrevistada. $\mathrm{O}$ roteiro incluiu os dados gerais das participantes, bem como aspectos ligados à escolaridade, trajetória e formação, e da educação infantil no município (avanços, conquistas, desafios, problemas). Ao final de cada entrevista, foi aplicado um instrumento solicitando, por escrito, informações relativas ao perfil da entrevistada, tais como: setor de atuação, nome do cargo, tempo de exercício na função, tempo de magistério e formação.

Em carta enviada a cada secretário de Educação, foi solicitada a indicação dos gestores responsáveis pela educação infantil do seu município. Com a indicação, foram entrevistados 73 profissionais: 71 mulheres e 2 homens. Essa razão motiva a identificação "entrevistadas", na forma feminina.

Todos as 73 indicações atuavam como gestores e como tal foram entrevistadas. Contudo, no momento das entrevistas, apenas 67 profissionais se identificaram como gestoras. Dessas, 48 informaram ocupar cargos ligados à gestão da educação infantil e 19 na gestão de outras etapas da educação básica ou em outros setores da Secretaria da Educação; 6 se identificaram como professoras, dizendo, por exemplo, "estou neste cargo de supervisão, mas sou professora". Desse modo, embora todas as profissionais atuassem como gestoras quando entrevistadas, algumas assim não se apresentaram, o que pode expressar a precariedade ou a fragilidade do vínculo 
institucional existente em alguns municípios. Não foi observada a interferência desse modo de se apresentar no conteúdo dos depoimentos.

No entanto, para o delineamento do perfil das entrevistadas neste texto, estão sendo consideradas, nos Quadros 1 e 3, apenas aquelas que se idenficaram como gestoras da educação infantil (48 profissionais), enquanto no Quadro 2 foram contabilizados todos os 73 entrevistados. Diferentes nomes foram encontrados para cargos com funções análogas. Aquelas que se identificaram como gestoras da educação infantil informaram ocupar os seguintes cargos:

\section{Quadro 1 - Cargos na gestão da educação infantil}

\begin{tabular}{|l|r|}
\hline \multicolumn{1}{|c|}{ Nome dos cargos } & Número de profissionais \\
\hline Apoio operacional de serviços de educação infantil/SME* & 1 \\
\hline $\begin{array}{l}\text { Assessora pedagógica da educação infantil e } \\
\text { coordenadora pedagógica/SEMEC** }\end{array}$ & 1 \\
\hline Assessora técnica do setor de pré-escola & 1 \\
\hline Chefe da divisão de educação infantil/SEME**** & 4 \\
\hline Coordenadora das creches municipais & 1 \\
\hline Coordenadora de educação infantil/SME & 18 \\
\hline Coordenadora da equipe de implementação de educação infantil/SME & 1 \\
\hline Coordenadora de gestão participativa & 1 \\
\hline Diretora da divisão de educação infantil/SEMEC & 1 \\
\hline Gestora das creches municipais/SME & 1 \\
\hline Implementadora de educação infantil/SME & 14 \\
\hline Orientadora educacional da equipe de pré-escola/SME & 2 \\
\hline $\begin{array}{l}\text { Supervisora da educação infantil e do primeiro } \\
\text { segmento do ensino fundamental/SME }\end{array}$ & 1 \\
\hline Supervisora de creches/SME & 1 \\
\hline Total de gestores & 48 \\
\hline
\end{tabular}

Fonte: Banco de dados da pesquisa/Perfil das entrevistadas, 2009.

Elaboração das autoras.

* Secretaria Municipal de Educação (SME); ** Secretaria Municipal de Educação e Cultura (SEMEC); *** Secretaria

Municipal de Educação (SEME).

Entre as gestoras de outras etapas da educação básica ou que atuavam em outros setores das secretarias de educação, havia também diferentes nomes para cargos com funções análogas ou similares, tais como diretora de ensino, diretora do departamento de educação, coordenadora articuladora, chefe das equipes técnico- pedagógicas, coordenador de educação especial, implementadora da educação básica, subsecretária de educação, supervisora de ensino da rede municipal, superintendente pedagógica.

Observa-se assim que a maioria das entrevistadas atuava no nível central, em cargos de supervisão, orientação e coordenação, ou chefia, superintendência e subsecretaria. Pela dispersão dos nomes combinada à semelhança de função e atividades desempenhadas, optou-se por se referir às profissionais como gestoras. 
Quanto à escolaridade, a situação identificada foi a seguinte.

Quadro 2 - Escolaridade das entrevistadas: curso de graduação ou pós-graduação concluído

\begin{tabular}{|c|c|c|c|}
\hline \multicolumn{4}{|c|}{ Nível de escolaridade } \\
\hline \multicolumn{2}{|c|}{ Graduação } & \multicolumn{2}{|l|}{ Pós-Graduação } \\
\hline Área & Número & Área & Número \\
\hline Ciências biológicas & 3 & $\begin{array}{l}\text { Administração escolar, orientação } \\
\text { e supervisão escolar }\end{array}$ & 12 \\
\hline Educação artística & 1 & Clínico institucional & 1 \\
\hline Fonoaudiologia & 1 & Educação infantil & 12 \\
\hline História & 2 & Educação para o pensar & 1 \\
\hline Letras & 8 & Gênero e diversidade na escola & 1 \\
\hline Matemática & 4 & Gestão escolar & 8 \\
\hline Normal superior & 9 & Mestrado em educação & 1 \\
\hline Pedagogia & 39 & Mestrado em educação matemática & 1 \\
\hline Psicologia & 1 & Políticas sociais & 1 \\
\hline Serviço social & 1 & Psicopedagogia & 11 \\
\hline Não informado & 9 & Terapia familiar & \\
\hline & & $\begin{array}{l}\text { Docência no ensino } \\
\text { fundamental e médio }\end{array}$ & 1 \\
\hline & & Literatura & 1 \\
\hline & & Não especificado & 3 \\
\hline & & Não informado & 3 \\
\hline Total & $78^{*}$ & Total & $58^{* *}$ \\
\hline
\end{tabular}

Fonte: Banco de dados da pesquisa/Perfil das entrevistadas, 2009.

* Cinco entrevistadas possuíam dupla formação.

* Cinco entrevistadas possuíam dupla titulação e três possuíam tripla titulação.

Elaboração das autoras.

O Quadro 2 permite dizer que, apesar da dispersão nas áreas de formação, a expressiva maioria das participantes da pesquisa apresentava curso superior de graduação e pós-graduação. Sobre a formação em nível médio, 18 declararam ter curso de formação de professores, e apenas 1 entrevistada declarou esta como sua única formação. Em que pese a escolaridade informada, várias entrevistadas mencionaram a precariedade da formação de gestores da educação infantil.

Foi também levantado o tempo de trabalho no cargo, município, educação infantil e magistério, como mostra o quadro seguinte.

\section{Quadro 3 - Tempo de trabalho das entrevistadas}

\begin{tabular}{|l|r|r|r|r|}
\hline \multicolumn{1}{|c|}{ Tempo } & No cargo & No município & $\begin{array}{c}\text { Na educação } \\
\text { infantil }\end{array}$ & No magistério \\
\hline Até 1 ano & 26 & 2 & 5 & \\
\hline Até 5 anos & 17 & 5 & 5 & 8 \\
\hline Até 10 anos & 4 & 18 & 8 & \\
\hline
\end{tabular}

(continua...) 
(...continuação)

\begin{tabular}{|l|r|r|r|r|}
\hline \multicolumn{1}{|c|}{ Tempo } & No cargo & No município & \multicolumn{1}{c|}{$\begin{array}{c}\text { Na educação } \\
\text { infantil }\end{array}$} & No magistério \\
\hline Até 15 anos & & 6 & 11 & 9 \\
\hline Até 20 anos & & 7 & 9 & 13 \\
\hline Até 25 anos & & 6 & 4 & 9 \\
\hline Até 30 anos & 2 & 3 & 4 \\
\hline Acima de 30 & 1 & & 1 & 4 \\
\hline Não informado & 48 & 2 & 2 & 1 \\
\hline Total & 48 & 48 & 48 \\
\hline
\end{tabular}

Fonte: Banco de dados da pesquisa/Perfil das entrevistadas, 2009.

Elaboração das autoras.

Pode-se notar que a maioria das entrevistadas possuía experiência de trabalho nas escolas da rede pública dos municípios e muitas continuavam atuando como professoras, coordenadoras e diretoras, em paralelo ao trabalho nas secretarias, configurando uma dupla inserção nas redes. Os relatos permitiram destacar a descontinuidade política entre governos, a privatização do espaço público e a existência de acordos políticos orientando indicações de gestores da educação infantil sem formação nem experiência. $O$ pouco tempo no cargo pode ser indício dessa descontinuidade.

Delineado o contexto e quem fala nas entrevistas, cabe agora serem ouvidos e analisados os relatos. É o que faz o item a seguir.

\section{O QUE DISSERAM AS ENTREVISTADAS}

Que avanços, conquistas, desafios e problemas foram enfrentados pela gestão municipal da educação infantil nos últimos dez anos? Diante dessa indagação, as gestoras falaram, nas entrevistas, de gestão, formação, concepção de educação infantil, criança e família. Vale reafirmar que o foco neste artigo é a gestão.

As subcategorias definidas na análise dos eventos discursivos foram as seguintes: gestão da rede e cobertura do atendimento; condições (recursos financeiros, materiais e espaço físico); descontinuidade ou continuidade política; organização da secretaria municipal de educação e da rede; funcionamento da secretaria e vínculos; relação das secretarias com as instituições; gestão da rede na proposta pedagógica; acesso à educação infantil; lugar social ocupado pela educação infantil na secretaria; profissionais de educação infantil, condições de trabalho e formação.

Muitas entrevistadas falaram da gestão da rede e cobertura do atendimento, da abrangência da oferta de educação infantil por parte das secretarias municipais de educação, da extensão das redes municipais, dos modos, critérios e motivos da expansão da oferta nos últimos anos e a preocupação com a demanda, comentando estratégias de ampliação do atendimento à demanda crescente. Muitos eventos discursivos expressaram como é forte a relação estabelecida entre a expansão da oferta de atendimento à educação infantil e a qualidade das condições da rede entre elas, o espaço físico. 
Segundo os relatos, a ampliação da oferta de vagas se concentrava majoritariamente na pré-escola, em detrimento da oferta para creche. Os municípios adotavam como estratégias de ampliação a inserção de turmas de educação infantil em escolas de ensino fundamental e o atendimento em turno parcial, o que possibilitava contabilizar maior número de matrículas. A expansão da oferta de educação infantil na última década e seus impactos na gestão foram os principais pontos destacados pelas entrevistadas. "Então a gente cresceu tanto, que se espantou quando viu o número. Porque a gente precisa dar suporte a essas escolas", disse uma gestora. "Criança brota no chão", "não vou dar conta dessa demanda toda", "aí cai a qualidade", "há um inchaço na rede", "lista de espera", desabafaram outras.

De acordo com as entrevistas, as principais estratégias dos governos municipais para aumentar a oferta de vagas na educação infantil eram a construção de novas creches e escolas e a ampliação da rede por meio de aluguel de casas e prédios. A municipalização de instituições estaduais foi citada também como uma forma de crescimento da rede. Contudo, entre essas estratégias, a que mais chama a atenção é a oferta de tempo parcial em vez de integral, assumida pelos governos municipais como uma forma de expansão. Assim, as formas de expansão citadas foram desde as iniciativas mais efetivas até as que ocorriam pela precarização do atendimento.

Nós temos escolas de tempo integral, que são as creches, mas a gente vê que às vezes se faz necessário acabar o tempo integral para atender mais criança, porque, quando a gente não tem o tempo integral, você atende mais uma turma, então o pai fica contente. A gente fica triste, porque para a gente deveria ser todos de tempo integral, mas infelizmente a gente não tem condições.

Outra gestora relatou: "Tínhamos essa luta em relação às creches, porque no nosso governo anterior a política era de inaugurar uma creche a cada dois meses, independente da condição". "A creche" - disse outra gestora - "era o carro-chefe".

Para as entrevistadas, a expansão ocorria em virtude da exigência da população - que cobrava seu direito por meio de ações judiciais - e de razões políticas, pois a oferta de educação infantil vinha sendo instrumento de projeção política para prefeitos. "Tem gente que não se preocupa com a qualidade, e sim com a quantidade; que politicamente rende muitos votos". [...] "E também tem o Ministério Público e o Conselho Tutelar, que não estão querendo saber se tem vaga, se não tem vaga. Eles exigem".

Muitas afirmaram que não era possível atender à demanda por educação infantil no município e as filas de espera por vaga nas instituições geravam, segundo elas, preocupação por parte da gestão. Nesse contexto, houve municípios que adotaram como critério para a expansão a prioridade para a pré-escola. A creche foi apresentada em várias entrevistas como desejo ou necessidade de expansão ainda não possível de ser concretizada pelo seu alto custo: "Verdade seja dita: bebê de fralda é uma despesa enorme".

Várias entrevistadas falaram das condições referindo-se aos recursos financeirose materiais, às verbas de que os municípios dispunham para gerir a educação infantil, 
e ao espaço físico. Segundo relataram, havia parcerias com instituições privadas e com o governo federal, mas os municípios enfrentavam dificuldades financeiras, já que os governos municipais são a principal instância provedora da educação infantil.

É uma pobreza. Agora o FUNDEB² está chegando [e] a educação infantil que temos é uma rica educação infantil, é com nosso recurso. A rede inteira tem mais de dez anos. Sempre foi com recurso próprio, podemos chamar assim, e não com FUNDEF $^{3}$ e com o FUNDEB.

Quando a pesquisadora perguntou se o município já tinha planos para a verba do FUNDEB, a entrevistada contou: "Nós pensamos em dias melhores. Este é o primeiro ano do FUNDEB".

Quanto aos recursos materiais disponibilizados pelas secretarias para as instituições, os depoimentos e os dados obtidos evidenciaram haver melhoria progressiva quanto ao fornecimento de livros, brinquedos e merenda, tema que se aproxima da questão do espaço físico e sua maior ou menor adequação às crianças e à natureza do trabalho realizado na educação infantil. Muitas entrevistadas destacaram a precariedade dos espaços físicos e a existência de demandas específicas, como berços e lactário, em uma escola de educação infantil.

Como os espaços escolares eram frequentemente adaptados ou alugados, tornava-se difícil atender a essas especificidades.

Espaço péssimo, muito pequeno, uma casa pequena, em tempo integral, um único banheiro, com único chuveiro, que faltava água direto. Uma criança que entra às $7 \mathrm{~h}$ da manhã e é pega às $17 \mathrm{~h}$, você imagina... $\mathrm{E}$ os cômodos pequenos, e dividindo cômodos, usando até a garagem para aproveitar espaço, dividindo espaço com armários. Um depósito de crianças, com aspecto horroroso.

As entrevistadas entendiam - com razão - que "o ideal aqui seria ter outro prédio de creche", "para a gente poder atender com qualidade e tranquilidade". "[Para atender crianças de 6 meses a 1 ano], tem que ter berço, tem que ter uma estrutura".

As falas relativas ao espaço físico afirmaram que os municípios adotavam estratégias como adaptações, ampliações, construções e aluguel de espaços. As construções pareceram ser impulsionadas pelo Programa Nacional de Reestruturação e Aquisição de Equipamentos para a Rede Escolar Pública de Educação Infantil (Proinfância), programa do governo federal que dá assistência financeira aos municípios para a estruturação da rede física das instituições de educação infantil. $O$ aluguel de espaços (quase sempre inadequados) ainda era opção frequente entre os

2 Fundo de Manutenção e Desenvolvimento da Educação Básica e de Valorização dos Profissionais da Educação.

3 Fundo de Manutenção e Desenvolvimento do Ensino Fundamental e de Valorização do Magistério. 
municípios pesquisados; contudo, algumas entrevistadas mencionaram a redução gradativa dessa prática.

Houve municípios que paulatinamente abriam turmas de educação infantil em escolas de ensino fundamental como estratégia de oferta de mais vagas, mas segundo as falas -, enquanto o ensino fundamental parecia ter prioridade no uso dos espaços, "a educação infantil tenta encontrar o seu lugar", como mostraram diferentes entrevistas.

O espaço [das turmas de educação infantil em escolas de ensino fundamental] é aquele bem feinho, é um espaço separado, é o que sobrou.

É porque aquele espaço não vai ser adequado para a educação infantil. A prioridade do espaço vai ser para o ensino fundamental, no máximo a gente vai ter uma salinha, talvez com as cadeirinhas adaptadas, os móveis, mas o espaço em torno não vai ser para a educação infantil.

Porém, essa medida de política pública exigia, segundo as gestoras, cuidados e providências práticas a serem tomadas nas instituições, no que se referia à organização e ao funcionamento nos espaços disponíveis.

A gente não quer isso [escolas de educação infantil e de ensino fundamental separadas], mas que se possa proporcionar uma estrutura para as duas funcionarem. Porque, se tem um pátio, esse pátio você divide com a educação infantil e com os alunos também do fundamental, com os maiores [...]. Precisa ter uma estrutura também para isso. Essas têm sido algumas das reivindicações propostas pela educação infantil e a gente tenta buscar atender isso: estrutura física.

"Isso" significa espaço físico digno e adequado. Falando "disso", as gestoras mostraram conhecer as necessidades e direitos das crianças a espaço e infraestrutura. Ao tratar da construção de um prédio exclusivo para a educação infantil, uma entrevistada comentou: "É realmente voltada para a educação infantil. Muito interessante, eu fiquei muito feliz. Quando me fizeram o convite [de assumir a direção de uma escola só de educação infantil], eu falei: 'Nossa, que audácia!"'

Muitas entrevistadas se referiram ao delicado tema da continuidade ou descontinuidade política dos grupos no poder e a decorrente permanência ou alternância dos profissionais nos cargos da secretaria. As entrevistadas trataram das consequências das trocas de governo; do modo como os cargos eram ocupados; da interferência de políticos na contratação de pessoal e na distribuição dos cargos; das relações e dinâmicas internas da equipe de educação infantil e das secretarias de educação; dos modos de interação entre os profissionais das secretarias e os profissionais das creches e pré-escolas, fossem estas instituições próprias da rede ou conveniadas; e das características da proposta pedagógica dos municípios.

O funcionamento das secretarias pareceu ser regido pelo calendário eleitoral. Trocas de governo foram apontadas como fator de fragmentação do trabalho 
e justificativa para o desconhecimento de informações sobre a educação infantil no município.

Então, até manter essa estrutura e essas trocas de governo, a gente sente muito. É geral também, não é só aqui.

Eu queria até informar a vocês que eu estou exatamente há dois meses na coordenação do município e diante disso algumas coisas eu até fico impossibilitada de dizer.

Uma coisa importante, um ponto que eu considero muito legal, privilégio, é que são três mandatos e a coordenação é a mesma, isso deu um caráter de continuidade importantíssimo ao trabalho.

Como na pesquisa de Nunes e Kramer (2007a), a indicação política para o cargo de diretor e a interferência de políticos na gestão também estiveram presentes nos relatos, mas as entrevistadas ressaltaram a intenção de romper com tais práticas. Uma gestora disse: "Outra coisa é você ter o poder próximo, especialmente vereadores próximos. Isso é um carma. [A interferência] é violenta”. Algumas gestoras mencionaram tentativas de romper com essas condutas.

Pois é isso mesmo que temos aqui [interferência dos políticos na gestão], mas estamos conseguindo cortar. Isso acontece muito na educação infantil. Até o próprio Conselho Tutelar também não tem uma noção de como organizar isso. Muitos pedidos e a gente sem conseguir atender. Ainda tem interferência desse tipo, mas estamos conseguindo dar uma organizada. No ensino fundamental não temos tanto isso, já que a rede oferece e supre a demanda, e ainda sobra.

Observa-se a consciência da gestora de que a interferência se dava pela falta de vagas, ou seja, na lacuna da ação do estado, modos patriarcais ou patrimoniais, fisiologismo e nepotismo ocupam o lugar de processos democráticos.

A organização da secretaria municipal de educação e da rede foi outro aspecto destacado: as gestoras se referiram ao modo de trabalho das coordenações de educação infantil e às equipes. A tônica das falas dizia respeito ao tamanho da equipe da educação infantil em relação à demanda de trabalho: em certos casos, a equipe havia aumentado; em outros havia necessidade de redimensionar e aumentar o número de pessoas.

E no início, em 2001, essa equipe era maior. Hoje em dia a gente está numa luta, uma equipe duo, duas pessoas só; já houve um momento em que o movimento era muito maior. Duas pessoas para 29 creches?

Também foram feitas referências à proximidade e boa articulação com outros setores das secretarias de educação. Como exemplificou uma gestora: 
Aqui funciona e a gente está junto com todo mundo. E tudo é organizado. Se eu precisar de um dado, eu vou à estatística, tem. Se eu precisar de alguma coisa, eu vou aqui à parte de informática, eles fazem.

As entrevistadas, ao contarem sobre a sistematização e estrutura, enfatizaram a diversidade de formas de organização das redes municipais de educação e dos profissionais (professores, auxiliares, coordenadores, orientadores, supervisores, inspetores). De acordo com os relatos, variavam também as atribuições de cada uma dessas funções, a formação exigida, a carga horária e as formas de contratação.

Em relação à organização das crianças em turmas, foram inúmeras as formas de agrupamento citadas, os nomes dados às turmas, a distribuição das turmas de educação infantil nos espaços escolares, fosse como estratégia para suprir a demanda por vagas, fosse por concepções pedagógicas. Vários municípios haviam escolhido ter todas as turmas de educação infantil em escolas de ensino fundamental, outros gradativamente abriam turmas de educação infantil em escolas de ensino fundamental, como alternativa de oferecer mais vagas, e outros municípios haviam optado por ter espaços exclusivos de educação infantil. As formas de organização variavam de um município para outro e também dentro de um mesmo município, conforme as opções de cada gestão. Assim,

Nós temos a característica das antigas creches que passaram para o sistema municipal, e em determinado momento viraram Centro de Educação Infantil (CEI) integral. Nós temos escolas só de educação infantil, e nós temos escolas de primeiro segmento que têm turmas de educação infantil, e cada um com uma concepção diferente. [...] Temos cinco escolas parciais só de pré-escola.

Mesmo que novas orientações de organização de cada rede fossem definidas pela gestão vigente, de acordo com os depoimentos, escolhas de gestões anteriores coexistiam com as atuais. As marcas de cada gestão se concretizavam nas formas de organização das turmas nos espaços, no nome desses espaços, nos tipos de construção, nas formas de contratação dos profissionais, no nome dos cargos. Penduravam-se na palavra "gestão" como franjas, configurando-lhe muitos sentidos (Bakhtin, 1988).

Diferentes nomes foram usados, em diferentes municípios, para se referirem à educação das crianças de $0 \mathrm{a} 6$ anos. Os termos estabelecidos em lei ("creche" para educação da criança de 0 a 3 anos; e "pré-escola" para educação da criança de 4 a 6 anos) não foram usados sempre com o significado definido. Muitas distorções foram notadas ou escutadas: creche podia significar horário integral, independentemente da faixa etária atendida. Em alguns casos, a creche significava a educação de crianças de 0 a 3 anos, mas não era referida como parte integrante da educação infantil.

Muitas entrevistadas trataram do funcionamento da secretaria e vínculos referindo-se ao modo como os cargos eram ocupados no município. Sobre os profissionais que atuavam nas secretarias, foi possível perceber a diversidade de vínculos estabelecidos com as redes que dirigiam: havia profissionais concursados, 
não concursados, convidados pela competência ou por razões políticas, "por se tratar de um cargo de confiança”.

Para vocês terem uma noção, esse é o primeiro governo em que nós temos um secretário de educação da rede, professor da rede. Na maioria das vezes, o que vinha acontecendo? Chamava-se uma pessoa de fora ou que tivesse uma relação político-partidária com alguém que conseguiu a eleição ou que era diretor de escola particular. Agora, conhecedor da rede, de trabalhar na rede, essa é a primeira gestão com essa característica.

As entrevistadas apontaram embates decorrentes da diversidade de vínculos dos profissionais que atuavam nas escolas, com falas sobre a precariedade dessa condição (grande número de contratos e a não realização de concursos), a diversidade de funções, a carga horária e o salário dos profissionais. Uma gestora comentou: "o professor regente, ele é concursado, ele vai para o CEI e trabalha quatro horas. Tem um salário $\mathrm{x}$. $\mathrm{O}$ agente de apoio trabalha oito horas e tem um salário y, bem reduzido. Então, começa aquela situação”. Outra ainda mencionou: "a nossa realidade hoje é uma realidade que a gente não tem professor concursado para trabalhar com a creche...”

Outro tema pertinente aos vínculos se referiu ao cargo de diretor. Em alguns municípios, os critérios pareceram pouco definidos e prevalecia a indicação; em outros era valorizada a profissionalização para esse cargo, com a exigência de formação superior.

Sobre a forma de funcionamento da equipe de educação infantil e da secretaria de educação, no que diz respeito às relações internas, dois foram os aspectos marcantes: o tamanho da equipe em relação às demandas de trabalho e as mudanças de gestão referentes à continuidade e descontinuidade. Para que as demandas de trabalho fossem cumpridas, segundo as entrevistadas, profissionais se dispunham a fazer atividades que não eram de sua alçada, ou que não deveriam ser executadas daquela forma:

Porque nós estamos aqui todos os dias. Antigamente a gente resolvia até problema de caixa d'água. Explodiu a caixa d'água, era com a gente; aquela situação, aquela coisa toda, e que consome; e você não consegue ver o resultado daquilo. A gente não consegue, muitas vezes, vislumbrar essas mudanças.

Estamos procurando [um espaço para alugar, para funcionar uma creche]. A subsecretária, na semana passada, saiu um dia inteirinho buscando isso. Passou o dia inteiro. Com o dinheiro dela, gastando a gasolina dela.

Tal situação pareceu resultar da falta de recursos humanos e materiais, do número insuficiente de pessoas nas equipes de educação infantil, da incompatibilidade entre a demanda de trabalho na secretaria e a carga horária dos profissionais. Relacionando esse problema com a qualidade do trabalho, uma gestora disse: "Às vezes a gente gostaria de ir mais vezes às escolas, e só não é possível por conta do 
número de pessoas. A gente faz visitas periódicas para acompanhar como é que está o trabalho lá na creche". Outra gestora confirmou: "A nossa carga horária aqui são doze horas semanais, de concurso mesmo. Nós fizemos concurso para trabalhar doze horas semanais. O problema é esse: se a gente ficar oito horas em formação, só vai ficar quatro horas aqui".

Além do excesso de atividades e da exigência de tarefas que extrapolavam a natureza do cargo, as situações citadas produziam um impacto significativo na forma como as equipes de educação infantil acompanhavam as escolas.

A gente está fazendo um núcleo de coordenação. Eu fui chamada. Como a rede tem creches conveniadas, então não tenho condições de dar conta. Tenho outra pessoa junto comigo, que também faz parte da coordenação, que trabalha com as creches conveniadas. Eu nem posso muito falar da creche conveniada, porque ainda não estou integrada na questão da creche. [Tinha] uma coordenadora de tudo e acharam melhor fazer a separação. Então, ela ficou com creche conveniada; me chamaram para estar atuando com as creches do município até a pré-escola.

Foram recorrentes os relatos sobre o impacto das mudanças de governo. As entrevistadas falaram de continuidade e descontinuidade de equipe e também de trabalho realizado.

$\mathrm{Na}$ mudança de governo, a minha equipe (éramos sete) foi toda desfeita. As minhas seis companheiras foram para outros lugares e a coordenadora acabou ficando com uma das minhas meninas. Outras foram para escolas, outras que eram contratos temporários tiveram que sair da rede e só continuaram duas da equipe; eu e outra menina ficamos na equipe da pré-escola. Logo em seguida fomos convidadas, novamente, para dirigir essa escola municipal e, como eu queria voltar a trabalhar na secretaria, a outra menina aceitou e eu continuei aqui. Então, das sete, hoje tenho eu da equipe da pré-escola.

Ao lado da grave situação de diminuição na equipe, chamou a atenção a menção da entrevistada ao pronome "minhas" e a identificação das profissionais como "meninas", aspectos que convergem com as conclusões de Nunes e Kramer (2007a, p. 448). Em pesquisa realizada em 2000 , as autoras constataram um modo de constituição da identidade de profissionais de educação infantil que enfatizava a minoridade dessas profissionais e as aproximavam das crianças a quem sua atuação se dirigia.

As gestoras comentaram ainda as formas de funcionamento das redes municipais quanto à diversidade de arranjos, supervisão das creches conveniadas, autonomia do professor no uso do referencial da rede, autonomia da escola na gestão da verba, orientação teórica (trabalho com projetos, cantos temáticos, conteúdos). As falas refletiram a pluralidade de organização das redes, a presença ou não de orientador pedagógico nas escolas; a presença ou não de auxiliar nas turmas 
de educação infantil; as funções dos professores e auxiliares; nomenclaturas dos auxiliares e critérios de organização das turmas de creche e pré-escola em turnos integral ou parcial.

Outro ponto citado foi a preocupação de organizar e documentar as ações da secretaria, como os eventos com participação de crianças ou de formação. Foram feitas referências à participação no Fórum de Educação Infantil e à parceria com a União dos Dirigentes Municipais de Educação (UNDIME).

Outra categoria identificada nas entrevistas dizia respeito à relação das secretarias com as instituiçôes. As entrevistadas trataram do cotidiano da gestão das instituições sob responsabilidade das secretarias municipais de educação, dos modos de interação entre os profissionais das secretarias e os profissionais das creches e pré-escolas e dos propósitos dessa interação. Segundo relataram, as principais estratégias usadas pelas secretarias para manter contato com as instituições eram visitas às creches e escolas e reuniões com um ou mais profissionais da equipe das instituições. Entre os profissionais, foi destacada a figura do supervisor, que faz a interface entre o pessoal das secretarias e os profissionais das escolas. As reuniões e visitas, em geral, aconteciam com dois propósitos: adequar a atuação do professor à proposta da secretaria e ouvir e buscar atender às demandas da comunidade escolar, numa perspectiva participativa de gestão.

Nós fizemos um último encontro de diretores e especialistas que foi muito interessante, porque nós começamos um processo de construção de uma agenda nova junto com eles, ouvindo os diretores, ouvindo os coordenadores.

A gente visita as escolas, mas uma vez por mês tem reunião com o supervisor, onde a gente passa material, onde a gente vê qual o trabalho está sendo feito na escola, tudo dentro do referencial, que nada pode fugir.

Receptividade ou resistência por parte das profissionais das escolas às propostas da secretaria estiveram presentes. Algumas enfatizaram o compromisso da equipe, das pessoas da escola, dos orientadores, dos professores, dizendo, por exemplo, que "toda proposta que a gente coloca em pauta eles abraçam".

O interessante é isso; você vai num lugar de educação infantil e você pode acompanhar o que está realmente acontecendo, o que foi proposto e todo mundo abraçou. Você chega numa unidade trabalhando determinado tema, você vai ver nas paredes do lado de fora das creches, das unidades, a maneira como aquilo foi apresentado, como aquilo está sendo trabalhado com as crianças. $\mathrm{O}$ grupo acreditar numa proposta e desenvolver, isso é um ganho muito grande para a equipe.

Outro tema que emergiu nas entrevistas foi a gestão da rede na proposta pedagógica. Muitos eventos discursivos fizeram referência à proposta pedagógica dos municípios: como a proposta era vista; como foi ou estava sendo o processo de 
construção; que documentos eram tomados como fontes; quais os motivos para a construção da proposta e que aspectos ou conteúdos eram priorizados.

Duas tendências foram observadas na construção das propostas: uma enfatizava o processo coletivo; outra destacava a necessidade de uma ação mais diretiva. Em alguns momentos, a proposta pedagógica foi descrita como um documento que apresentava conteúdos e o perfil de trabalho; em outros foi caracterizada por uma construção coletiva, na qual os professores, a comunidade educativa e os pais colocavam seus desejos.

Para muitas entrevistadas, a proposta pedagógica era um processo, um caminho, "algo flexivel" e em construção. Foram recorrentes as falas que percebiam a proposta pedagógica como resultado do movimento de construção coletiva, com a participação de professores e diretores, levando em conta o trabalho que já vinha sendo feito pelos profissionais das redes. Esse modo de entender uma proposta foi vista por muitos como uma conquista.

Quando a gente chegou aqui, não tinha nada; não tinha proposta pedagógica, controle dos mínimos de ensino fundamental, assim a gente tinha que começar realmente a construir. Construção solitária para mim não é construção, tem que ser uma coisa coletiva, que todos tenham voz, possam opinar qual o caminho. Então nós fomos fazendo isso com os professores; junto com os professores nós fomos estudando as diretrizes curriculares da educação infantil, parâmetros, e dali fomos pegando o que a gente acredita; acreditamos que na educação infantil o foco tem que ser este.

No entanto, outras entrevistadas afirmaram que em seus municípios havia necessidade de propostas mais diretivas pela dificuldade de construírem a proposta coletivamente ou pela opção de um referencial que viesse da secretaria.

Nós esperávamos um pouquinho mais, esperávamos que eles dessem um pouco mais para essa construção, mas eles sentiam falta do papel [diretriz pedagógica feita pela secretaria]. Ficavam esperando nós levarmos o papel.

Quando houve essa reunião em que apresentamos essa proposta de educação infantil, eles [os professores] adoraram porque viram espaço para pedir uma base para nós.

Distribuímos um material todo mastigadinho para os professores trabalharem.

O início da fala "Quando a gente chegou aqui, não tinha nada", da mesma maneira que "esse é o primeiro governo que...", aproximou-se do significado da expressão "a história começa quando eu entro nela", presente em um dos relatos de profissionais que atuavam também na gestão da educação infantil, como foi apontado por Nunes et al. (2005).

Entre os documentos que fundamentaram a construção das propostas, foram citados a LDB, o Referencial Curricular Nacional de Educação Infantil, os 
Parâmetros Curriculares Nacionais (PCNs) e os Parâmetros de Qualidade para a Educação Infantil, além de documentos construídos anteriormente pela própria rede.

A motivação para a construção da proposta pedagógica pareceu expressar a necessidade de normatização da rede. Em relação aos conteúdos presentes na proposta, as entrevistadas citaram: "desenvolvimento integral da criança", "desenvolvimento de habilidades e competências" e "conteúdos mínimos a serem trabalhados". Fizeram referência ainda a propostas organizadas por temas, áreas de conhecimento, projetos de trabalho, linguagens e campos do saber. Apenas dois depoimentos citaram temas relativos à brincadeira, linguagem e cultura ou à concepção de criança como sujeito social - embora estes fossem temas centrais de documentos de muitos municípios.

$\mathrm{O}$ acesso à educação infantil emergiu nos relatos como direito da criança (conquista legal, desde a Constituição Federal de 1988). Contudo, o entendimento da creche como benefício para as mães trabalhadoras também esteve presente. Diante da impossibilidade de atender à demanda, o critério usado em muitos municípios vinha sendo o de priorizar crianças com mães trabalhadoras.

Como estamos ampliando, eu não estou dando vaga apenas para aquela mãe que está trabalhando, a gente está dando vaga também para aquela que está procurando emprego. Para ela ter tempo. Como ela vai bater de porta em porta para pedir emprego com uma criança do lado? Ninguém vai dar. Hoje a creche não tem mais só aquela mãe que está trabalhando, tem também as mães que estão querendo estudar, trabalhar. A demanda é muito grande porque é uma educação infantil para todos. A gente não está fechando, como no início, só as que trabalham. A procura é muito grande.

Descobrimos que existem mais mulheres trabalhando do que homens. E essa mulher que trabalha, essa mãe que trabalha, precisa de um abrigo para os seus filhos.

Alguns municípios utilizavam outros critérios de preenchimento de vagas, tentando uma aproximação com a lógica dos direitos da criança. Mas, como não havia vagas para todos, o que mudava era o lugar da exclusão.

A deliberação que a gente tem [sobre critérios para a entrada na creche] ainda é de 2006, os critérios preestabelecidos ali ainda estão muito vinculados ao assistencialismo. Como, por exemplo, a mãe estar trabalhando seria um critério. Nós resolvemos não obedecer esse ano. Passamos a aceitar por ordem de chegada. A educação é para todos.

Sobre o lugar social ocupado pela educação infantil na estrutura das secretarias de educação, houve convergência nas falas. Em grande parte das entrevistas, a educação infantil foi descrita como um segmento novo que passou, nos últimos anos, a desfrutar de reconhecimento e de valorização manifestada nos investimentos e na visibilidade dada para essa etapa diante dos demais segmentos. 
Os avanços são muitos, principalmente o foco está todo voltado para essa primeira etapa agora. Acho que a bola da vez está com a gente. Acho não, tenho certeza; chegou a hora, e nós temos que aproveitar o momento.

[...] a educação infantil é um bebê dentro da educação. E ainda estamos aprendendo a lidar e tentando construir alguma coisa.

Houve relatos também sobre o lugar da educação infantil, que era - segundo as gestoras - manifestado por pessoas da comunidade e profissionais da secretaria. Algumas entrevistadas destacaram a qualidade do trabalho realizado no município, que se tornava visível na "felicidade das crianças em frequentar as instituições", "na felicidade dos profissionais" de trabalharem nessa etapa de escolarização e na "satisfação dos pais", que preferiam colocar seus filhos em escolas da rede municipal em vez de escolas particulares.

Eu sinto que as crianças das nossas creches são felizes. Elas gostam da creche, estão sempre brincando.

A educação infantil do município é de uma qualidade, os pais consideram de uma qualidade, que não veem uma necessidade de colocar numa escola particular.

Muitas ambiguidades marcaram os relatos sobre os convênios. Foram diversas as modalidades de conveniamento citadas, de um município para outro ou dentro do próprio município; as instituições conveniadas podiam receber dinheiro, profissionais, material; e podiam ou não ser supervisionadas pela equipe de educação infantil da secretaria. $\mathrm{O}$ evento discursivo a seguir explicita a ambiguidade em uma entrevista com duas gestoras.

São características diferenciadas de convênio. Então, uma [creche] que é conveniada com a prefeitura, e o convênio dela seja receber só o professor, esse professor é da rede municipal, e ele vem para fazer a formação a partir do momento que ele quiser. Agora, em outras situações de convênios, é só a cessão do prédio. Quer dizer, nem sempre eles [os professores] chegam à secretaria.

Às vezes é uma ajuda per capita, por criança.

Ou às vezes é só a merenda.

Tem 1 instituição que recebe o espaço físico. Tem 19 instituições que recebem merenda, tem 1 instituição com transporte escolar, tem 19 instituições que recebem pagamentos e ajuda de custo.

Caso extremo foi o de um município cuja equipe não tinha conhecimento da existência de creches conveniadas.

As entrevistadas abordaram também as condições de trabalho e a formação dos profissionais da educação infantil. De acordo com os depoimentos, a identidade desses profissionais pode aqui ser analisada quanto às características pessoais desejáveis para o exercício da profissão, quanto à atuação e especificidade do trabalho e quanto à formação. 
No que diz respeito às características desejáveis para ser professora, gostar do trabalho pareceu ser um traço definidor da identidade das profissionais de educação infantil, como se esse fator fosse um requisito, como se, gostando de crianças, todas as dificuldades pudessem ser vencidas, mesmo sem formação adequada. "Se você não gosta do que faz, sai, procura outra coisa. O pior é fazer malfeito". [...] "Ela adora criança e não está encontrando um mínimo de dificuldade". Essa visão se aproximou do estudo de Cerisara (1996) sobre a construção da identidade dos profissionais de educação infantil.

De acordo com as gestoras, o baixo salário levava os profissionais a trabalharem em duplas jornadas, fosse no mesmo município ou em municípios vizinhos.

[...] porque a gente sabe que fica cansativo, os professores ficam muito cansados, a verdade é essa; a realidade que nós tentamos compreender aqui é que eles ficam muito cansados. Tem muito professor que trabalha aqui e [cita dois municípios] ou é professor da rede [municipal] e do estado. Tem uma professora aqui que é até interessante: ela é professora de educação infantil, mas é professora de arte no estado; ela não abre mão dessa turma de educação infantil e no estado ela dá aula em mil e uma turmas. Então, o que a gente nota é muita falta de tempo e cansaço.

Segundo as entrevistadas, não havia concurso específico para a educação infantil. Muitas profissionais acabavam trabalhando nessa etapa de escolarização sem desejar.

Faz um concurso e o que sobra é o que vai para educação infantil.

A creche ainda não é muito bem aceita pelos profissionais; elas se sentem inferiores. [...] Parecia que eu estava desmerecendo o professor em colocar ele no pré.

O movimento contrário também pareceu acontecer. Havia professores que, cansados da cobrança e do trabalho nas séries iniciais, optavam por atuar na educação infantil imaginando encontrar ali um trabalho mais fácil.

Nós temos o rodízio nas escolas; o professor trabalha na escola um tempo com o ensino fundamental, então ele resolve que não quer mais trabalhar com o ensino fundamental, já que as crianças estão muito agitadas, e decide ir para a educação infantil. Isso é uma realidade de Brasil, não é só daqui... "Esse meu aluno não vai me responder, então eu vou para lá trabalhar com essa criança que é fácil, é moleza”, sem ter noção do trabalho pedagógico que deve ser desenvolvido dentro da educação infantil.

Tanto nesse movimento de ingresso no magistério da educação infantil como no movimento de saída, alguns profissionais - segundo as gestoras - pareciam colocar o trabalho realizado nessa etapa num lugar hierarquicamente inferior ao realizado no ensino fundamental. Para as entrevistadas, havia profissionais que 
pareciam não se sentir valorizados por atuar na educação infantil. A discussão sobre formação permeou a questão da valorização desse profissional.

A formação esteve presente em muitos relatos e análises, tanto a formação inicial dos profissionais de educação infantil quanto ações de formação continuada realizadas apenas pelos municípios ou em parceria com outros órgãos. Aqui, posições opostas pareceram coexistir. Em vários eventos discursivos, as entrevistadas reforçaram a imagem de que professor gosta de estudar e busca níveis de formação mais elevados, mesmo sem exigência ou remuneração. Outras afirmaram o contrário. "Os professores adoram encontro de formação", "Os nossos cursos têm que ter cara e corpo de oficina para dar 'ibope'. Se disser que é somente para estudar...”

A formação exigida pelos municípios para atuar como professor de educação infantil ainda foi citada como muito diversa, bem como as formas de contratação desse profissional.

O pré-requisito [para o cargo de professor de educação infantil, no concurso que pretendem abrir] é que ela tenha uma especialização em educação infantil, curso de formação específica para educação infantil. Nós colocamos a quantidade de horas. Não basta ser um curso de quarenta horas, nós queremos o pessoal da educação infantil.

Para professor não [se exige ensino superior], só ensino médio. Temos sim professor com ensino superior, monitor com ensino superior e até concluindo o ensino superior, mas isso não foi um pré-requisito para a contratação.

Apesar de haver referências que exaltavam o aumento do nível de escolaridade dos professores de educação infantil, quando o tema é a qualidade da formação, esta ainda pareceu ser considerada insuficiente ou inadequada.

Como trabalham o dia inteiro, não têm condições de buscar uma faculdade federal, estadual, porque demanda tempo. Essas faculdades [públicas] geralmente têm aulas de dia, e elas procuram sábado. Elas procuram mais uma faculdade particular por isso, por esse tempo que elas disponibilizam.

Quem está formada há um ano, dois anos... Poucos sabem escrever com coerência, coordenação lógica de ideias, poucos, apenas 10\%, eu te digo, ninguém nasce sabendo.

Tem professores entrando agora na rede e que estão trabalhando e não sabem nem o que é o referencial curricular de educação infantil.

A formação frágil acabava por acarretar dificuldades no trabalho com as crianças, de acordo com as gestoras. As entrevistadas falaram de uma dupla situação: professoras com muita teoria e pouca prática, ou sem teoria, mas que poderiam aprender em seu caminho profissional. Os eventos a seguir trazem essa tensão. 
É que, às vezes, esse profissional não foi preparado para a educação infantil. Porque o que se pensa na faculdade é na teoria, estudar os grandes pensadores, os grandes educadores, que a gente tem que ter também. Porque a gente tem que ter o embasamento. Você tem que explicar o porquê de estar fazendo e entender também o porquê de você estar fazendo aquilo. Mas a prática, esqueceram. Que eram coisas que a gente sempre teve. A prática está sendo na sala de aula.

Esse profissional [professor] que trabalha lá, que não é concursado, é um profissional que não tem a teoria, tem a boa vontade e quer acertar. Isso eu posso falar com muita clareza; eu estou lá, estou dentro da creche. É um profissional que quer acertar, mas que não sabe como lidar com a parte educativa da creche.

A gente sente uma dificuldade muito grande, não sei se você percebe isso também. Professores mais antigos, que estão assim em vias de se aposentarem, parecem que já não têm fôlego; [para] trabalhar com educação infantil, você tem que ter fôlego, a criança está em constante movimento, e os novos que estão se formando agora têm uma formação muito ruim mesmo.

As entrevistadas trouxeram detalhes sobre como a formação era realizada, os temas abordados, quem participava dos encontros, as parcerias estabelecidas, os diversos modos de organizar a formação dos profissionais: cursos, oficinas, encontros, reuniões, simpósios. Nota-se que havia uma tendência a encontros mais eventuais quando o público era formado por professores, e encontros mais sistemáticos para diretores, supervisores e orientadores, muitas vezes com o intuito de que esses profissionais organizassem a formação nas escolas.

Um ponto controverso: a maior parte das entrevistadas afirmou oferecer formação aos profissionais nos seus municípios, mas as secretarias municipais tinham dificuldade de garantir condições para que os professores efetivamente participassem da formação. Houve, pois, municípios que pareceram contar com a iniciativa dos profissionais e outros que, apesar de reconhecerem a responsabilidade da secretaria em viabilizar a participação dos professores, não desenvolviam ações nesse sentido.

Lá [na Casa do Educador] eles podem se inscrever o quanto eles quiserem. Agora, tem que ter tempo. Funciona de segunda a sábado, três horários.

Em outro horário, mas desde que nós pensássemos nessa remuneração, que é difícil. É difícil o profissional largar tudo, largar criança, largar casa, ele tem filho, tem uma porção de coisa. E você vai, só gasta o dinheiro da passagem, sem incentivo, volta, vê. Acaba ficando... Eu digo para elas que elas são guerreiras, de vez em quando estão aí, você olha para cara de uma, chega aqui às terças-feiras, elas chegam assim... "O que foi?”"Nada, não". Porque você tem que ter um jogo de cintura para poder se segurar... 
Segundo algumas entrevistadas, os municípios tinham planos de cargos e salários que revertiam a formação progressiva dos profissionais em ganhos salariais. Muitas fizeram observações em que a formação e as condições eram lados de um mesmo processo, um só desafio, tal como quando uma das gestoras entrevistadas disse encontrar "professores antigos sem fôlego, novos sem preparo". Mais uma vez, a ambivalência que marcou as falas foi evidenciada.

\section{CONSIDERAÇÕES FINAIS: AVANÇOS E URGÊNCIAS}

Este artigo resulta de uma pesquisa voltada para as políticas públicas municipais na gestão da educação infantil. Com base em entrevistas com profissionais atuantes nas secretarias de educação de 24 municípios e valendo-se também de dados obtidos por meio de outros instrumentos, foi possível identificar que houve avanços no que se refere (a) à expansão das matrículas nas creches públicas; (b) à organização e funcionamento de muitas secretarias de educação que assumiram a especificidade da educação e da educação infantil; (c) à formação de equipes pedagógicas de acompanhamento da educação infantil. Observou-se o envolvimento das equipes que atuavam diretamente com crianças de 0 a 6 anos em projetos de formação, indicando investimento crescente na qualificação dos profissionais. Contudo, os relatos mostraram muitas ambiguidades.

As entrevistas possibilitaram afirmar que são urgentes: a abertura de concurso específico para professor de educação infantil; processos democráticos de nomeação de diretor, em especial nas creches; plano de cargos e salários compatível com a função docente; melhoria nas condições das instituições; formação das equipes de gestão.

A abertura de concursos para professores e auxiliares que atuem com crianças na educação infantil é exigida por lei. Como é exigida a formação em nível de ensino superior, admitindo-se o ensino médio na modalidade normal, compete ao município a realização de concurso específico para professor de educação infantil. Ou seja, há legislação no Brasil que regula a realização de concurso público específico para professor de educação infantil e garantia de, no mínimo, um professor por turma, com direito a aperfeiçoamento profissional continuado, piso salarial profissional, progressão funcional baseada na titulação ou habilitação, período reservado a estudos, planejamento e avaliação incluído na carga de trabalho e condições adequadas de trabalho. Porém, não foi isso o que se ouviu nas entrevistas.

Além disso, os municípios pesquisados não apresentaram tradição de realizar concurso para funções de gestão - supervisor, orientador ou coordenador - nas secretarias ou nas instituições, passo importante para se constituir e consolidar equipes de gestão da educação infantil e do ensino fundamental nos municípios.

Outro aspecto se refere aos processos de nomeação de diretor. $\mathrm{O}$ princípio legal de gestão democrática do ensino público não era seguido em grande parte dos municípios pesquisados. $\mathrm{O}$ cargo de direção das instituições de educação infantil não era, em geral, ocupado com base em critérios claros, tornados públicos, com 
a participação da comunidade escolar. $\mathrm{O}$ uso partidário ou as interferências de interesses locais de grupos específicos prevalecia na indicação.

Foram percebidos, pelos relatos, municípios sem plano de cargos e salários, apesar da exigência legal. Profissionais da educação infantil atuavam com as crianças sem qualificação para o exercício da função docente. Muitos foram tratados não como professores, mas por apelidos que remetiam a relações de parentesco, amizade ou infantilização.

Continuidade ou descontinuidade política e permanência ou alternância dos profissionais nos cargos das secretarias motivaram muitas falas. As gestoras denunciaram as consequências das trocas de governo, o modo como os cargos eram ocupados, a interferência de políticos na contratação de pessoal e na distribuição dos cargos, as dinâmicas internas das equipes de educação infantil nas secretarias de educação, os modos de interação entre profissionais das secretarias e das creches, pré-escolas e escolas. As trocas de governo foram apontadas como fator de fragmentação do trabalho e como justificativa para o desconhecimento das informações sobre a educação infantil. Foram percebidos conflitos decorrentes da diversidade e precariedade de vínculos dos profissionais que atuavam nas escolas, da falta de isonomia de carga horária e salários. A proposta pedagógica foi descrita ora como documento que apresenta conteúdos e o perfil de trabalho, ora como uma construção coletiva de professores, comunidade educativa e pais.

Em virtude do baixo salário, as participantes da pesquisa trabalhavam em dupla jornada, no mesmo município ou em municípios vizinhos.

Segundo os relatos, na ampliação da oferta de vagas em creches, pré-escolas e escolas, muitas secretarias de educação optavam por adaptar ou alugar imóveis sem condições adequadas para o trabalho de qualidade com as crianças e sem atender a definições legais das especificidades da educação infantil. A precariedade do espaço físico e a existência de demandas específicas não atendidas resultavam com frequência dessa opção.

Alguns municípios mantinham turmas de educação infantil somente em escolas de ensino fundamental; outros gradativamente abriam turmas de educação infantil em escolas de ensino fundamental como estratégia de oferta de mais vagas; outros ainda mantinham espaços exclusivos de educação infantil.

Embora tenha havido aumento significativo de redes municipais com equipes nas secretarias atuando especificamente com creche e pré-escola, nas entrevistas as profissionais referiram-se à instabilidade dessas equipes voltadas para a educação infantil, compostas não por critérios que levassem em conta a experiência e o conhecimento relativo à rede pública e à educação infantil, mas por relações políticas, de parentesco ou interesses locais.

No momento em que este texto foi finalizado (abril de 2012), diversos temas relativos à educação infantil ocupavam o centro da cena dos debates educacionais. Tanto no âmbito das políticas públicas quanto nas diversas formas de manifestação da mídia, discute-se hoje a ampliação da escolaridade obrigatória dos 4 aos 17 anos, a reorganização administrativa provocada também por essa ampliação nas redes 
públicas e privadas, que buscam redefinir a idade de ingresso no ensino fundamental. Observa-se ainda a premiação de economistas que têm defendido a importância das creches no cenário nacional e internacional, baseados em extensas bases de dados.

Esses temas por vezes se somam e por vezes se contrapõem aos grandes desafios enfrentados por aqueles que atuam como gestores e professores no cotidiano das creches, pré-escolas e escolas, bem como das secretarias de educação e das instâncias intermediárias. Os resultados da pesquisa permitiram visualizar que ainda há uma grande distância entre o que se espera e o que propõem a legislação e os documentos oficiais em relação à gestão democrática, acesso, condições e formação dos profissionais.

As entrevistas permitiram notar a diversidade e a desigualdade que constituem as políticas municipais. Em meio à fragilidade das condições e à precarização dos equipamentos sociais em diversos municípios, há profissionais que resistem e lutam por um trabalho de qualidade com crianças de 0 a 6 anos. Municípios pequenos, com arrecadações baixíssimas, avançam nas discussões da educação infantil e priorizam a infância e o trabalho do professor de educação infantil.

Como pesquisadoras, assumimos o papel de procurar conhecer o real e compreendê-lo; como profissionais da educação, nosso desejo é ver a melhoria do atendimento às crianças pequenas, diminuindo as desigualdades e o sofrimento. Ainda que as entrevistas não tenham sido capazes de tal feito, puderam deixar os conflitos e tensões aparentes. Esperamos que a pesquisa e a discussão desses resultados contribuam para as políticas de educação infantil, para as equipes de professores e gestores e, sobretudo, para as crianças. Essa é a maior motivação da equipe e o eixo do nosso compromisso.

\section{REFERÊNCIAS}

Andre, Marli Eliza Dalmazo Afonso de. Avanços no conhecimento etnográfico da escola. In: Fazenda, Ivani Catarina Arantes (Org.). Pesquisa em educação e as transformações do conhecimento. Campinas: Papirus, 1995. p. 99-110.

Bakhtin, Mikhail. A cultura popular na Idade Média e no Renascimento: o contexto de François Rabelais. São Paulo: Editora Hucitec, 1987.

. (Voloshinov, Valentin Nikolaevich). Marxismo e filosofia da linguagem. São Paulo: Editora Hucitec, 1988.

. Estética da criação verbal. São Paulo: Martins Fontes, 1992.

Ball, Stephen J.; Mainardes,Jefferson (Orgs.). Politicas educacionais: questões e dilemas. São Paulo: Cortez, 2011.

Brasil. Constituição da República Federativa do Brasil. Brasilia,DF, 5 out. 1988. Disponível em: <http://www.planalto.gov.br/ccivil_03/Constituicao/Constitui\%C3\%A7ao.htm>. Acesso em: 7 jul. 2010. 
Lei n. 9.394, de 20 de dezembro de 1996. Estabelece as diretrizes e bases da educação nacional. Brasília, DF: Diário Oficial da União, 23 dez. 1996. Disponível em: <www.planalto.gov.br/ccivil_03/Leis/L9394.htm>. Acesso em: 7 jul. 2010.

Cerisara, Ana Beatriz. A construção da identidade dos profissionais e educação infantil: entre o feminino e o profissional. 1996. 184 f. Tese (Doutorado em Educação) - USP, São Paulo, 1996.

Nunes, Maria Fernanda; Santos, Patrícia; Vargens, Paula; Kramer, Sonia. Gestão da educação infantil: "a história começa quando eu entro nela". In: Kramer, Sonia. Profissionais de educação infantil: gestão e formação. São Paulo: Ática, 2005. p. 100-120.

Nunes, Maria Fernanda; Kramer, Sonia. Gestão pública, formação e identidade de profissionais de educação infantil. Cadernos de Pesquisa, São Paulo: Fundação Carlos Chagas; Campinas: Autores Associados, v. 37, n. 131, p. 423-454, maio/ago. 2007a.

Gestão municipal e formação: a educação infantil no estado do Rio de Janeiro. Revista Brasileira de Estudos Pedagógicos, Brasília: INEP, v. 88, n. 218, p. 48-72, jan./abr. 2007b.

Vasconcellos, Vera Maria Ramos de; Aquino, Ligia Maria Leão de; Lobo, Ana Paula Santos Lima Lanter. A integração da educação infantil ao sistema de ensino: exigências e possibilidades pós-LDB. In: SouzA, Donaldo Bello de; FArIA, Lia Ciomar Macedo de (Orgs.). Desafios da educaşão municipal. Rio de Janeiro: DP\&A, 2003. p. 235-258.

\section{SOBRE AS AUTORAS}

Sonia Kramer é doutora em educação pela Pontifícia Universidade Católica do Rio de Janeiro (PUC-Rio). Professora associada da mesma instituição. E-mail:sokramer@puc-rio.br

Leonor Pio Borges de Toledo é doutoranda em educação pela Pontifícia Universidade Católica do Rio de Janeiro (PUC-Rio).

E-mail: leonorptoledo@gmail.com

Camila Barros é mestre em educação pela Pontifícia Universidade Católica do Rio de Janeiro (PUC-Rio).

E-mail: barros.camila@gmail.com

Recebido em maio de 2012

Aprovado em março de 2013 


\section{RESUMOS/ABSTRACTS/RESUMENS}

\section{SONIA KRAMER, LEONOR PIO BORGES DE TOLEDO E CAMILA BARROS}

\section{Gestão da educação infantil nas políticas municipais}

Este artigo apresenta pesquisa sobre políticas públicas e gestão da educação infantil. Focaliza entrevistas realizadas com profissionais responsáveis pela educação infantil em secretarias de educação de 24 municípios. Após apresentar o referencial teórico-metodológico, a concepção de entrevista e como esta foi desenvolvida na pesquisa, o artigo descreve o contexto analisado, o perfil das entrevistadas e analisa os principais resultados, relativos à gestão e cobertura do atendimento, condições (recursos financeiros, materiais e espaço físico), continuidade política, organização e funcionamento das secretarias municipais de educação, relações entre secretarias e instituições, gestão da proposta pedagógica, acesso à educação infantil, lugar social da educação infantil, profissionais de educação infantil, condições de trabalho e formação. Ao final, sistematiza conclusões e prioridades para políticas públicas.

Palavras-chave: gestão pública; educação infantil; políticas municipais.

Early childhood education management in municipal policies

This paper presents a study on public policies and early childhood education management. It focuses on interviews with professionals responsible for early childhood education who worked in education departments in twenty-four cities. After presenting the theoretical-methodological framework, the conception of interview and the way it was developed, the article describes the research context, the profile of respondents and analyses the main results concerning: the management and coverage of education services; conditions (financial resources, equipment and space); political continuity; organization and operation of municipal education departments; relations between departments and institutions; management of pedagogical proposals; access to early childhood education; the social role of early childhood education; early childhood education professionals; working conditions and training. At the end, the article systematizes conclusions and public policy priorities.

Keywords: public management; early childhood education; municipal policies.

Gestión de la educación infantil en las políticas municipales

Este articulo presenta una investigación sobre politicas puiblicas y gestión de Educación Infantil. Se centra en las encuestas con profesionales responsables por la educación para niños en veinticuatro departamentos municipales de educación. Después de presentar el referencial teórico-metodólogico, la concepción de entrevista y como se há desarrollado, el artículo describe 
el contexto de la investigación, el perfil de los encuestados y analiza los principales resultados en cuanto a: gestión y extensión de atención; condiciones (recursos financieros, materiales y espacio); continuidad politica; organización y operación de los departamentos municipales de educación; relaciones entre departamentos e instituciones; gestión de la propuesta pedagógica; acceso a la educación infantil; lugar social da educación infantil; profesionales de educación infantil, condiciones de trabajo y formación. En la última parte, sistematiza conclusiones y prioridades para politicas públicas.

Palabras clave: administración pública; educación infantil; politicas municipales. 